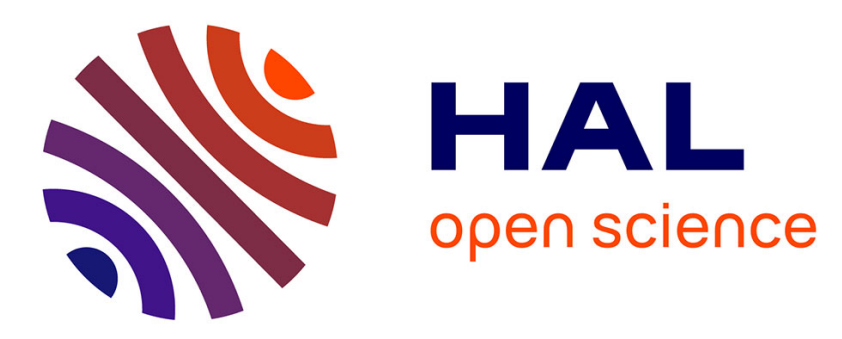

\title{
The Unity of Focus: Evidence from Sign Language (ASL and LSF)
}

Philippe Schlenker, Valentina Aristodemo, Ludovic Ducasse, Jonathan

Lamberton, Mirko Santoro

\section{- To cite this version:}

Philippe Schlenker, Valentina Aristodemo, Ludovic Ducasse, Jonathan Lamberton, Mirko Santoro. The Unity of Focus: Evidence from Sign Language (ASL and LSF). Linguistic Inquiry, 2016, 47 (2), pp.363-381. 10.1162/LING_a_00215. hal-03509841

\section{HAL Id: hal-03509841 \\ https://hal.science/hal-03509841}

Submitted on 7 Jan 2022

HAL is a multi-disciplinary open access archive for the deposit and dissemination of scientific research documents, whether they are published or not. The documents may come from teaching and research institutions in France or abroad, or from public or private research centers.
L'archive ouverte pluridisciplinaire HAL, est destinée au dépôt et à la diffusion de documents scientifiques de niveau recherche, publiés ou non, émanant des établissements d'enseignement et de recherche français ou étrangers, des laboratoires publics ou privés. 


\section{The Unity of Focus: \\ Evidence from Sign Language (ASL and LSF) ${ }^{*}$}

Philippe Schlenker ${ }^{\mathrm{a}}$, Valentina Aristodemo ${ }^{\mathrm{b}}$, Ludovic Ducasse, Jonathan Lamberton $^{\mathrm{c}}$, Mirko Santoro ${ }^{\mathrm{b}}$

Revised, October 6, 2015 - To appear in Linguistic Inquiry

In spoken languages, focus (i) is normally realized by phonological prominence, which in English is effected by higher pitch, greater loudness and longer duration (e.g. Katz and Selkirk 2011). Semantically, it (ii) signals the activation of alternatives (e.g. Rooth 1996), and (iii) it has diverse effects, ranging from contrastive (as in (1)a) to exhaustive (as in (1)b). ${ }^{1}$

(1) a. I'll introduce John to Mary, and then I'll introduce BILL to her.

b. If you invite John OR Mary, the party will be a success.

$\Rightarrow$ no inference that the party will be a success if the addressee invites John AND Mary

Finally, it has been speculated that (iv) the realization of focus is driven by a biological 'effort code' whereby greater pitch excursions (and thus greater effort on the speaker's part) are associated with greater emphasis/importance; (Gussenshoven 2001, 2004). ${ }^{2}$

Following Wilbur 2012, as well as Crasborn and van der Kooij 2013 and Kimmelman 2014, we argue that versions of all four properties hold of ASL and LSF focus, which suggests that focus has a unified semantics and to some extent a unified semantics/phonology interface across modalities; in particular, contrastive and exhaustive focus can be realized by the same prosodic means. Earlier studies emphasized the diversity of focus realization in ASL, and the importance of syntactic movement (Wilbur 2012), which made it hard to isolate the role of prosody. By contrast, detailed production studies of Sign Language of the Netherlands (NGT) and Russian Sign Language (RSL) displayed in situ strategies of (corrective and informational) focus marking involving modulations of sign speed, size and duration, combined with non-manual markers in NGT (Crasborn and van der Kooij 2013;

\footnotetext{
${ }^{a}$ Institut Jean-Nicod (ENS - EHESS - CNRS) - Département d'Etudes Cognitives, Ecole Normale Supérieure - PSL Research University; New York University.

b Institut Jean-Nicod (ENS - EHESS - CNRS) - Département d'Etudes Cognitives, Ecole Normale Supérieure - PSL Research University; EHESS.
} 
Kimmelman 2014; see also Kimmelman and Pfau, to appear). We complement Wilbur's findings by studying particularly simple paradigms in which movement is inapplicable, and show that in these cases ASL and LSF sign modulations and non-manuals may also suffice to mark focus, with diverse semantic effects, ranging from contrastive to exhaustive, as in spoken language. Following in part Crasborn and van der Kooij 2013, we suggest that a version of the 'effort code' is arguably at work in ASL and LSF, with focused signs realized not just with raised eyebrows (as is standard), but also with greater amplitude, speed acceleration, and longer hold times, among others. Since ASL and LSF are both descended from Old French Sign Language, some important similarities between them are of course to be expected; but we still note some differences in our data, particularly the presence of forward leans in ASL but not in LSF (which, however, includes head nods).

Following the typology of Vallduví 1992, Wilbur 1999 establishes that in ASL "the primary indicator of stress marking is the significant increase in peak velocity of prominent signs $^{\prime 3}$ (p. 236), and that as in English "a single prominence is assigned to the right-most lexical item in the phrase" (p. 237), but that unlike in English prominence cannot be moved, with the result that focus is preferably realized by movement; in Wilbur's (and Vallduví's) terms, with respect to focus realization ASL is '[-plastic]', unlike English but like Catalan. In contrast to Wilbur's analysis of ASL, in production experiments Crasborn and van der Kooij 2013 (studying NGT) and Kimmelman 2014 (studying NGT and RSL) emphasized the role of non-movement-based strategies, in particular of prosody. In both studies, focus appeared in question-answer pairs or in corrective contexts (as in: The woman is eating chocolate, right? -The woman is eating

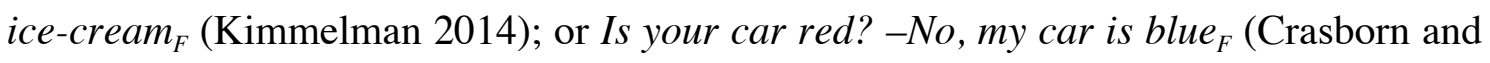
van der Kooij 2013). In Kimmelman's summary of his comparative data (p. 130), RSL focus primarily involves manual prosody, with modulations of size, speed and duration, as well as repetitions. NGT also uses these strategies (with different frequencies), but in

\footnotetext{
${ }^{\mathrm{c}}$ CUNY - Queens College.
} 
addition it makes use of non-manual prosody, involving eyebrow raising, backward head tilt, and head nod.

While Wilbur emphasizes the diversity of strategies of focus realization in ASL, we complement her observations by showing that in a subset of ASL and LSF cases in which movement in inapplicable prominence and non-manuals alone -including forward leans - can realize both contrastive and exhaustive focus, which makes for a particularly minimal comparison with English (some cases of in situ focus also appear in Wilbur and Patschke 1998 and Lillo-Martin and Quadros 2008). We selected two cases of focus that are semantically very different: instances of contrastive focus that do not involve association with any operator, and could be analyzed in terms of simple constraints on givenness (Schwarzschild 1999); and instances of embedded focused elements which trigger exhaustive readings in the scope of other operators, and would require, in the analysis of Chierchia et al. 2012, the insertion of exhaustivity operators with clear truth-conditional consequences. Importantly, we will see that despite these semantic differences, these two types of focus can be realized with the same prosodic means.

Methods and limitations: Our data were elicited from Lamberton for ASL and from Ducasse for LSF. Both are Deaf children of Deaf, signing parents, and they co-authored this piece. In contrast to the production experiments in Crasborn and van der Kooij 2013 and Kimmelman 2014, we obtained grammaticality judgments using the 'playback method', with repeated quantitative acceptability judgments $(1-7$, with $7=$ best $)$ and repeated inferential judgments (on separate days) on videos involving minimal pairs (for earlier uses of this method, see Schlenker 2013, 2014, to appear; Schlenker et al. 2013; Kuhn 2015). We asked each consultant to put emphasis on certain words, and thus the production part was artificial, just as it would be for the creation of experimental stimuli; but the subsequent (and repeated) judgment task (by the same consultant) made for minimal comparisons between appropriate and deviant sentences 
depending on the placement of focus marking. Like the standard 'introspective' method used in linguistics, our procedure provides some data that are hard or impossible to get in a production experiment, in particular: (i) clear minimal pairs in which the same expression occurs both in focused and in unfocused form; (ii) information about the deviance of sentences in which the 'wrong' expression is focused; and (iii) fine-grained information about the truth-conditional effects of focus. Our procedure improves in two respects on the standard 'introspective' method: first, the judgments are repeated and thus their stability over time can be assessed; second, the judgments are quantitative and thus more fine-grained than the standard partition into 'acceptable' and 'unacceptable' sentences. Still, our method has important limitations as well. First, due to the small number of consultants, we cannot make claims besides the native signers we collaborated with. In particular, any differences between our ASL and our LSF data could be due to robust differences between the two languages, or to the sort of crosssigner variation that can be found within one and the same language. Second, we cannot assume that our two consultants used the 7-point scale in the same way; when the same ordinal contrasts between two analogous sentences are found across consultants, this can be informative, but absolute acceptability scores should not be compared directly across consultants. Finally, we could only collect judgments on clusters of prosodic markers that were produced in our target videos, and hence we cannot draw inferences about the acceptability of other clusters that might have been produced under different circumstances or by other signers.

ASL data were transcribed by Lamberton himself; LSF data were transcribed by Aristodemo and Santoro, who are not native LSF signers but have experience working with LSF videos, and they consulted with Ducasse in some cases ${ }^{4}$. As is standard, sign language glosses are capitalized; $I X-i$ represents a pointing sign toward locus $i$ (usually to realize a pronoun, with $I X-1$ and $I X-2$ referring to the speaker and the addressee respectively); loci affixed to verbs represent agreement markers; a word signed in locus $i$ is glossed as $W O R D_{i}$. For reader-friendliness, we use a revised transcription system 
(the /-notation ${ }^{5}$ ) in which sign modulations are indicated by modifying the glosses themselves, while non-manuals appear above the capitalized glosses, with iconic symbols whenever possible - in the order: 1 . body changes 2 . head changes 3 . facial expressions, e.g. $/ \mu^{\wedge}$ :

(2) a. Non-manuals: $\quad /=$ forward lean; $\backslash=$ backward lean; $\$=$ raised shoulders $\}=$ head nod; $\wedge=$ raised eyebrows; $\sim=$ lowered eyebrows

b. Sign modulations: WORDS = greater amplitude; $[$ WORDS $=$ = longer hold time;

+ WORD or $+[$ WORDS] $+=$ speed acceleration

Except in if-clauses, non-manuals were only included on the focused words or in the corresponding controls. Average scores precede each sentence, with full judgments appearing as superscripts between curly brackets in the order in which they were obtained. Hence $4.2^{\{55335\}}$ refers to an average score of 4.2 obtained from raw scores 5, then 5, 3, 3, and 5. Unless noted otherwise, sentences included in the same numbered example were signed and evaluated as part of the same video and thus form minimal pairs. We have added footnotes when there was more than a 2-point gap among the scores obtained for a given sentence - but even in such cases the ordinal rankings among sentences with 'well-placed' vs. 'ill-placed' focus were very stable.

\section{Contrastive Focus}

\subsection{Contrastive focus in ASL}

In (3) and (4), we investigated examples in which the letter names $B$ and $J$ count as new in the second clause, while the other letter names count as given. As a result, standard theories (e.g. Schwarzschild 1999) predict that focus should be acceptable on $B / J$ but not on the other letters. (3)b and (4)b have focus on $B / J$, and they are indeed more acceptable than (3)a and (4)a, which have focus on the 'wrong' letter (the c-d examples are also degraded, as is expected, but they offer less minimal points of comparison because the signer used slightly different non-manuals). Importantly, $B$ is a relatively static sign, but $J$ involves movement, namely a rotation executed by the lower $\operatorname{arm}^{6}$. Since the /-notation is new, we will now explain on the example of (3) how it should be read. 
(3) Context: The speaker is an ASL instructor teaching students to fingerspell four-letter sequences. IX-2 WILL FINGERSPELL A C E D, FINISH ${ }^{7}$
a. $4.2^{\{55335\}}$
$-\stackrel{\wedge}{A}-_{-}^{-}$B E D
b. $7^{\{77777\}}$
A $\quad-\hat{\mathbf{B}}_{-}^{-}$E D
c. $4.2^{\{64434\}}$
A B $\quad-\frac{1}{\mathbf{E}_{-}^{-}}$D
d. $4.6^{\{63446\}}$
$\mathrm{A} \mathrm{B} \mathrm{E}-\frac{1}{+\mathbf{D}}$

'You will fingerspell ACED, then $\overline{A B E D . ' ~(A S L, ~ 21, ~ 52 ; ~} 5$ judgments)

In (3)a, $A$ was produced with greater than normal amplitude, which is encoded by boldfacing it $(\boldsymbol{A})$. It was also produced with a longer than normal hold time, hence $\boldsymbol{A}_{-}$. It was a accompanied with a forward body lean, hence the / that appears above $\boldsymbol{A}$, and it was accompanied with raised eyebrows, hence ${ }^{\wedge}$. The same remarks apply to the realization of $B$ in (3)b and of $E$ in (3)c: in the latter case, the raised eyebrows were replaced with lowered eyebrows, hence $\sim$ instead of $\wedge$. Finally, $D$ in (3)d was realized with greater amplitude and with a longer hold time, but also with speed acceleration, hence the + that precedes $\boldsymbol{D}$. It was accompanied with a forward body lean, but with neutral eyebrows. The same conventions apply to (4).

(4) Context: The speaker is an ASL instructor teaching students to fingerspell four-letter sequences. IX-2 WILL FINGERSPELL A C E D, FINISH
a. $4.4^{\{45445\}}$ $-\frac{/ \Lambda}{\mathbf{A}_{-}} \quad$ J E D
b. $7^{\{77777\}}$ A
E D
c. $4.2^{\{64434\}}$
A J
d. $4.6^{\{64436\}}$

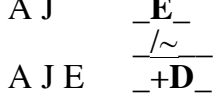

'You will fingerspell $A C E D$, then $A J E D$ ' (ASL, 21, 54; 5 judgments)

Turning to the analysis, since the letter names appear in a quoted sequence, we do not expect syntactic movement to affect their realization. Thus focus is solely realized by prominence, and it is acceptable on new but not on old elements - hence the higher ratings for (3)b and (4)b than for the other sentences, which have focus marking on the 'wrong' elements. In the acceptable examples, focused $B$ and $J$ involved (i) raised eyebrows; (ii) a forward lean, as in Wilbur and Patschke 1998 and Wilbur 2012; (iii) a longer hold time; and (iv) a greater sign amplitude. As we discuss below, (ii)-(iv) are compatible with a (possibly modified) version of Gussenhoven's 'effort code'. While (i) 
also exists in some spoken language focus constructions (Dohen 2005, Dohen and Loevenbruck 2009), its grammatical function in sign language is still debated (see Wilbur 2012 for references, and also Dachkovsky and Sandler 2009 for an analysis of Israeli Sign Language that likens raised eyebrows to $\mathrm{H}$ tones in spoken language).

In (5) and (6), different ('trembling') versions of fingerspelled letters are used to realize proper names (thus we write $A_{N N}$ to transcribe the trembled letter $A$ used to abbreviate this proper name); these names are used rather than mentioned, but since they are semantically conjoined, one also doesn't expect syntactic movement to be applicable - and the results support the same generalizations as the results found with the mentioned letter names in (3)-(4): focus marking on new elements in (5)b and (6)b is more acceptable than focus marking on old elements, as in the other sentences; and the same means are used to mark focus as in (3)-(4), except that in (5) (vs. (3)) speed acceleration replaces greater sign amplitude.

(5) Context: The speaker is trying to teach groups of students to work together.

TODAY IX-1 SEVERAL MEETING-rep FIRST MEETING $\mathrm{A}_{\mathrm{NN}} \mathrm{C}_{\mathrm{HARLES}} \mathrm{E}_{\mathrm{DITH}} \mathrm{D}_{\mathrm{ENIS}}, \mathrm{FINISH}^{8}$
a. $4^{\{4336\}} \frac{/ \Lambda}{+\mathrm{A}_{\mathrm{NN} \_\mathrm{a}}} \mathrm{B}_{\mathrm{ILL} \_\mathrm{b}} \mathrm{E}_{\mathrm{DITH} \_\mathrm{c}} \mathrm{D}_{\mathrm{ENIS} \_\mathrm{d}}$
b. $7^{\{7777\}} \mathrm{A}_{\mathrm{NN} \_\mathrm{a}} \quad-{ }_{-}+\mathrm{B}_{\mathrm{ILL} \_\mathrm{b}} \stackrel{1 \Lambda}{-} \mathrm{E}_{\mathrm{DITH} \_\mathrm{c}} \mathrm{D}_{\text {ENIS_d }}$
c. $3^{\{3324\}} \mathrm{A}_{\mathrm{NN} \_\mathrm{a}} \mathrm{B}_{\mathrm{ILL} \_\mathrm{b}} \quad-\overline{-\mathrm{E}_{\mathrm{DITH} \_\mathrm{c}}} \mathrm{D}_{\text {ENIS_d }}$
d. $3.2^{\{3325\}} \mathrm{A}_{\mathrm{NN} \_\mathrm{a}} \mathrm{B}_{\text {ILL_b }} \mathrm{E}_{\mathrm{DITH} \_\mathrm{c}} \quad-+\mathrm{D}_{\mathrm{ENIS} \_\mathrm{d}}$

'Today I have several meetings. My first meeting is with Ann, Charles, Edith and Denis, then with Ann, Bill, Edith and Denis.' (ASL, 21, 70; 4 judgments)

(6) Context: The speaker is trying to teach groups of students to work together.

TODAY IX-1 SEVERAL MEETING-rep FIRST MEETING $A_{\text {NN_a }} C_{\text {HARLES_b }} E_{\text {DITH_c }} D_{\text {ENIS_d }}$, FINISH
a. $5^{\{5456\}}-\overline{\mathbf{A}_{\text {NN_a- }}} J_{\text {OHN_b }} E_{\text {DITH_c }} D_{\text {ENIS_d }}$
b. $7^{\{7777\}} \mathrm{A}_{\mathrm{NN} \_\mathrm{a}}-\frac{\mathbf{J}_{\text {OHN_b }}}{\Lambda_{\text {OITH_c }}} \mathrm{E}_{\text {ENIS_d }}$
c. $3^{\{3324\}} \mathrm{A}_{\mathrm{NN} \_\mathrm{a}} \mathrm{J}_{\mathrm{OHN} \_\mathrm{b}} \quad \overline{+\mathrm{E}_{\mathrm{DITH} \_c}} \frac{/ \sim}{\sim} \mathrm{D}_{\text {ENIS_d }}$
d. $3.5^{\{3335\}} \quad \mathrm{A}_{\mathrm{NN} \_\mathrm{a}} \mathrm{J}_{\mathrm{OHN} \_\mathrm{b}} \mathrm{E}_{\mathrm{DITH} \_} \quad-\frac{1}{\mathrm{D}_{\text {ENIS_d }}-}$

'Today I have several meetings. My first meeting is with Ann, Charles, Edith and Denis, then with Ann, John, Edith and Denis' (ASL, 21, 71; 4 judgments) 
Our generalizations also hold of the mentioned word $O R$ in (7)c, which involves a forward lean, raised eyebrows, speed acceleration, and a longer hold time. Here too, focus marking on the new element (namely $O R$ ) in (7)c gives rise to a higher rating than focus marking on old elements (namely $A_{N N}$ and $B_{I L L}$ ) in (7)b, c (in addition, the sentence without contrastive focus marking in (7)a is acceptable too).

(7) Context: The speaker is an ASL instructor teaching students to sign 3-word sequences.
IX-2 WILL SIGN 'A ${ }_{\mathrm{NN} \_a}$ AN
a. $6.5^{\{7667\}} \mathrm{A}_{\mathrm{NN} \_\mathrm{a}}$ OR $\mathrm{B}_{\mathrm{ILL} \_b}$ '

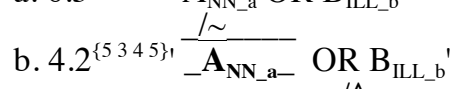
c. $7^{\{7777\}} \cdot \mathrm{A}_{\mathrm{NN} \_\mathrm{a}} \stackrel{+}{+\mathrm{OR}_{-}} \mathrm{B}_{\mathrm{ILL} \_\mathrm{b}}{ }^{\prime \wedge}$

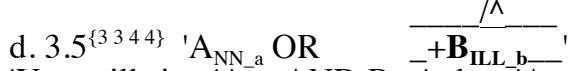

'You will sign ' $\mathrm{A}_{\mathrm{NN}}$ AND $\mathrm{B}_{\mathrm{ILL}}$ ', then 'A $\mathrm{A}_{\mathrm{NN}}$ OR B $\mathrm{B}_{\mathrm{ILL}}$ '.' (ASL, 21, 74; 4 judgments)

\subsection{Contrastive focus in $\mathbf{L S F}$}

Similar patterns are found in LSF, with some differences: (i) forward lean wasn't observed; by contrast, (ii) we found regular use of head nods to mark focus.

(8) Context: The speaker teaches fingerspelling to his students.

IX-1 WANT IX-2 FINGERSPELL A C E D THEN

a. $7^{\{77777\}}$ A B E D

b. $1.4^{\{113111\}} \quad \stackrel{-\}^{\wedge} \hat{+}_{-}^{\wedge}}{\text { B E D }}$

c. $7^{\{77777\}} \mathrm{A} \quad \stackrel{-\}^{\wedge}}{+\mathbf{B}_{-}}$E D

d. $\left.1.4^{\{1} 131111\right\}$ A B $\stackrel{-\}_{-}^{\wedge}}{+\mathbf{E}_{-}}$D

e. $\left.1.4^{\{1} 113111\right\}$ A B E ${ }_{-}^{-\}^{\wedge}}-$

'I want you to fingerspell $A C E D$, then $A B E D$ ' (LSF, 42, 69; 5 judgments)

In (9)b, the focused element was a proper name PIERRE (related to the noun for 'stone'); it involved a movement with greater amplitude, a longer hold time, and speed acceleration.

(9) Context: Every day, the speaker teaches his students to collaborate in pairs. ${ }^{9}$ TODAY IX-1 TEACH O OIVER JEAN MARIE TOMORROW

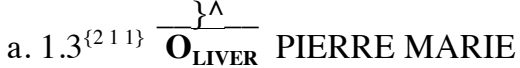

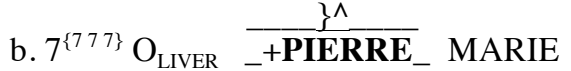

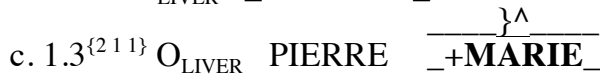
'Today I'll teach Oliver, Jean and Marie, and tomorrow I'll teach Oliver, Pierre and Marie.' (LSF, 42,$49 ; 3$ judgments) 
The same generalizations hold of the phone numbers in (10), where new digits but not old ones can be focused. ${ }^{10}$

(10) NUMBER TELEPHONE POSS-1
a. $7^{\{77777\}} \quad 0143435343$
b. $1.4^{\{11311\}}$
01
$-\frac{\gamma}{4}_{-}^{\wedge} 3435343$
c. $1.4^{\{11311\}}$
0143
$-\frac{\}^{\wedge}}{4} 35343$
d. $7^{\{77777\}}$
014343 - $\mathbf{5}_{-} 343$
e. $1.4^{\{11311\}} \quad 01434353 \stackrel{-\}^{\wedge}}{\mathbf{4}_{-}} 3$

'My phone number is 0143435343 .' (LSF, 42, 73; 5 judgments)

In sum, in the examples discussed in this section, contrastive focus was marked in both languages by raised eyebrows, accompanied with forward leans in ASL, and with head nods and greater sign amplitude in LSF. Greater sign amplitude was often seen in ASL as well, and longer hold times and speed accelerations were also commonly seen in both languages.

\section{Exhaustivity Focus in ASL and LSF}

We turn to the role of focus in triggering exhaustive readings. In the extant literature, exhaustivity effects in sign language were primarily studied in special constructions - in particular in question-answer pairs in discourse in Wilbur 2012, and single-sentence question-answer pairs in Caponigro and Davidson 2011 (a construction somewhat similar to pseudoclefts). In both cases, it is hard to decide whether the exhaustivity effect is due to focus marking per se or to the syntactic/pragmatic environment it is found in. Here we investigate constructions in which focus marking alone is responsible for the emergence of an exhaustive reading, one that would require the insertion of an exhaustivity operator in the framework of Chierchia et al. 2012.

\subsection{Exhaustivity focus in ASL}

The initial effect is seen in the contrast between neutral and focused $O R$ in (11)a-b. Judgments were accompanied with an inferential task to test whether $O R$ was in fact exclusive. 
(11) Context: The addressee is throwing a party. The speaker has some preferences as to who should be invited.

a. $6.8^{\{77677\}} \overline{\text { IF IX-2 INVITE } \bar{A}_{N_{n} a} \text { OR } \overline{B_{\text {ILL }}} \text { - if }}$ IX-1 WILL GIVE-2 $\$ 10$.

$\Rightarrow>$ if the addressee invites both Ann and Bill, the speaker has to give him $\$ 10$

b. $7^{\{77777\}} \overline{\text { IF IX-2 INVITE } A_{\text {NN_a }} \text { if } \overline{\text { OR }}-\bar{B}_{\text {ILL }} \text { - }}$, IX-1 WILL GIVE-2 $\$ 10$.

$\Rightarrow>$ if the addressee invites both Ann and Bill, the speaker doesn't have to give him $\$ 10$

'If you invite Ann or Bill, I'll give you \$10.' (ASL, 21, 76; 5 judgments)

In (11)a, no exclusive reading is available, which is unsurprising since $O R$ appears in a downward-entailing environment, where embedded implicatures are extremely limited. By contrast, in (11)b the exclusive reading is dominant with focused $O R$, realized with a forward lean, raised eyebrows ${ }^{11}$, greater amplitude and a longer hold time. These truthconditional effects are replicated under BET in (12). While BET does not create a downward-entailing environment, for pragmatic reasons it does not invite an embedded implicature; none is obtained without focus, but with focused $O R$ a clear effect emerges. $^{12}$

(12) Context: Tomorrow there will be a party. The speaker and the addressee make a bet about who will show up.

a. $7^{\{777\}}$ IX-1 BET A $A_{\mathrm{NN} \_\mathrm{a}}$ OR B B $\mathrm{ILL} \_\mathrm{b}_{\mathrm{b}}$ COME.

$=>$ if Ann and Bill come and nobody else comes, the speaker wins his bet

b. $7^{\{777\}}$ IX-1 BET A $A_{\text {NN_a }}-\frac{1 \Lambda}{+[\overline{\mathbf{O R}}]_{-}} B_{\text {ILL_b }}$ COME.

$\Rightarrow$ if Ann and Bill come and nobody else comes, the speaker doesn't win his bet ${ }^{13}$

'I bet that Ann or Bill will come.' (ASL, 24, 07; 3 judgments)

Interestingly, there are several other ways to form disjunction in ASL. In each case focus was acceptable, but we obtained inconsistent semantic judgments. Specifically, for a given sentence, there were often inconsistent inferential judgments from one trial to the next under $I F$, while exclusive readings were obtained under $B E T$; still, we don't conclude anything from the latter fact, as we have more judgments with IF than with BET, and those with $I F$ and BET which were obtained at the same time often gave rise to the same pattern. Such inconsistent results were obtained with: $O R$ WHICH (placed between and before the disjuncts), EITHER-OR (placed between and before the disjuncts), $O R-I X-I X$ (placed before the disjuncts), $O R-V$ (placed before disjuncts). We leave this empirical question for future research. 


\subsection{Exhaustivity focus in $\mathbf{L S F}$}

In our LSF data, focused $O R$ triggered an exclusive reading in conditionals ${ }^{14}$ (in (13)b, and also in (15)b) and under BET (in (14)); here too, LSF differs from ASL in that (i) no forward lean was perceptible in LSF, but (ii) heads nod were observed, and (iii) an upwards shoulder movement could sometimes be seen.

(13) Context: Tomorrow, there is a party. The speaker and the interlocutor make a bet about who will come.

a. $7^{\{777\}}$ PARTY $\overline{\text { IF PIERRE OR MARIE COME }}$ if $\overline{\text { if }} \overline{\text { CX-1 1-GIVE-2 }} 10$ EUROS.

$\Rightarrow>$ if both Pierre and Marie come, the speaker has to give the addressee 10 euros

b. $7^{\{777\}}$ PARTY $\overline{\text { IF PIERRE —-if }} \frac{\$\}^{\wedge}}{\text { OR }} \overline{\text { MARIE COME }} \overline{\text { if }}$ IX-1 10 EUROS 1-GIVE-2. ${ }^{15}$

$\Rightarrow>$ if both Pierre and Marie come, the speaker doesn't have to give the addressee 10 euros

'If Pierre or Marie come(s), I will give you 10 euros.' (LSF, 44, 23; 3 judgments)

(14) Context: Tomorrow, there is a party. The speaker and the interlocutor make a bet about who will come.

a. $7^{\{777\}}$ IX-1 BET PIERRE OR MARIE COME.

$\Rightarrow$ if Pierre and Marie come and nobody else comes, the speaker has won his bet

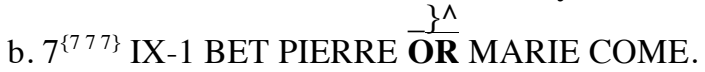

$=>$ if Pierre and Marie come and nobody else comes, the speaker hasn't won his bet

'I bet that Pierre or Marie will come.' (LSF, 44, 33; 3 judgments)

LSF can also realize disjunction with a postposed alternating pointing sign, $O R$ -

$I X_{a}-I X_{b}$. Interestingly, both in a conditional and under $B E T$, the focused version was just deviant, as seen in (15)-(16) (exclusive readings were obtained in the control sentences with a focused version of 'normal' $O R$ in $(15) \mathrm{c}, \mathrm{d}-(16) \mathrm{c}, \mathrm{d})$.

(15) Context: Tomorrow, there is a party. The speaker and the interlocutor make a bet about who will come. ${ }^{16}$

a. $7^{\{777\}}$ PARTY İF PIERRE OR MARIE COME, IX-1 10 EUROS 1-GIVE-2.

$\Rightarrow>$ if both Pierre and Marie come, the speaker has to give the addressee 10 euros

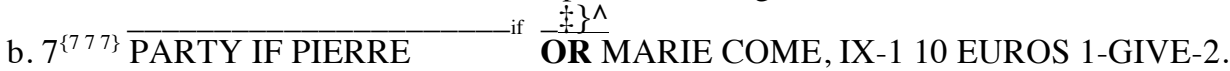

$=>$ if both Pierre and Marie come, the speaker doesn't have to give the addressee 10 euros

c. $7^{\{777\}} \overline{\text { PARTY IF PIERRE }} \overline{\text { MARIE }}_{\mathrm{a}} \overline{\text { OR-IX }}_{\mathrm{a}}-\overline{\mathrm{IX}}_{\mathrm{b}}$ COME IX-1 10 EUROS 1-GIVE-2.

$\Rightarrow$ if both Pierre and Marie come, the speaker has to give the addressee 10 euros

d. $2^{\{114\}} \overline{\text { PARTY IF PIERRE }}_{\mathrm{b}} \overline{M A R I E}_{\mathrm{a}}-\mathrm{if} \overline{\text { OR-IX }_{\mathbf{a}}-\overline{\mathbf{I X}}_{\mathbf{b}}}$ COME IX-1 10 EUROS 1-GIVE-2.

Intended: 'If Pierre or Marie come(s), I'll give you 10 euros.' (LSF, 44, 62; 3 judgments) 
(16) Context: Tomorrow, there is a party. The speaker and the interlocutor make a bet about who will come.

a. $7^{\{777\}}$ IX-1 BET PIERRE OR MARIE COME

$\Rightarrow>$ if Pierre and Marie come and nobody else comes, the speaker has won his bet

b. $7^{\{777\}}$ IX-1 BET PIERRE ${ }^{\}^{\wedge}}$ OR MARIE COME.

$=>$ if Pierre and Marie come and nobody else comes, the speaker hasn't won his bet

c. $7^{\{777\}}$ IX-1 BET PIERRE MARIE $_{\mathrm{a}}$ OR-IX $_{\mathrm{a}}$-IX $\mathrm{IX}_{\mathrm{b}}$ COME.

$\Rightarrow>$ if Pierre and Marie come and nobody else comes, the speaker has won his bet

d. $1.7^{\{113\}}$ IX-1 BET PIERRE MARIE $_{\mathrm{a}} \quad \overline{\mathbf{O R}-\mathbf{I} \mathbf{X}_{\mathrm{a}}-\mathrm{IX}_{\mathbf{b}}}$ COME.

Intended: 'I bet that Pierre or Marie will come.' (LSF, 44, 56; 3 judgments)

As things stand, we do not know why these effects hold. It is possible, but unlikely ${ }^{17}$, that there is something phonologically wrong with the focused version of $O R-I X_{a}-I X_{b}$. Alternatively, it could be that focusing on $O R-I X_{a}-I X_{b}$ fails to yield a semantic effect ${ }^{18}$ and is for this reason prohibited by some condition of economy. While we do not know why there should be such a difference between LSF $O R$ and LSF $O R-I X_{a}-I X_{b}$, we already noted that some ASL disjunctions failed to yield an exhaustive reading; it might be that the same effect is at work in LSF, but that our LSF consultant doesn't accept idle instances of focus.

In sum, in all the examples discussed in this section, exhaustive focus on (standard) $O R$ was marked in both languages by raised eyebrows and greater sign amplitude, accompanied with forward leans in ASL and head nods in LSF, and sometimes with a longer hold time or speed acceleration in ASL. In both languages, a clear truth-conditional effect was seen when standard $O R$ was embedded under ifclauses and under BET, as focus sufficed to trigger an exclusive reading.

\section{Discussion}

Our data lead to several positive conclusions about focus in natural language.

1. First, even though many ASL constructions reported in Wilbur 2012 express focus by a combination of syntactic and prosodic means, when movement is inapplicable, sign modulations and non-manuals can suffice to express focus. The same result was obtained in LSF - which as mentioned at the outset is historically related to ASL. ${ }^{19}$ 
2. Second, in each language a given cluster of non-syntactic modifications has contrastive and exhaustive effects alike, depending on the context. Furthermore, our acceptability and inferential tasks showed that putting contrastive focus on the 'wrong' expressions yielded deviance, and that exhaustive focus had fine-grained truthconditional effects. Plausibly, then, it is no accident that contrastive and exhaustive focus can be expressed by the same means in spoken language - this result appears to hold of language in general, including sign languages. ${ }^{20}$ It is certainly compatible with the view that focus just signals the activation of alternatives, and that further material (contrastive elements present in the discourse, or a covert exhaustivity operator) is responsible for semantic differences between the two cases.

3. Third, the phonological realization of focus in both languages is of theoretical interest:

-increased amplitude, speed acceleration, longer hold times, and raised eyebrows were found in ASL and LSF alike (very systematically for raised eyebrows and forward leans/head nods);

-forward leans were found in our ASL but not in our LSF data; head nods were found in LSF (and might or might not have been part of 'forward leans' in ASL); and a couple of instances of shoulder raising were found in LSF but not in ASL.

For methodological reasons mentioned at the outset, work with more signers will be needed to establish the robustness of these generalizations.

As mentioned, in spoken language higher pitch, greater loudness and longer duration can be used to express focus. Longer duration is found in sign language as well. One might or might not want to equate greater sign amplitude with greater loudness or speed acceleration with higher pitch. But certainly greater loudness, pitch and sign amplitude, as well as speed acceleration, can be taken to instantiate Gussenhoven's 'effort code'. On the other hand, forward leans (in ASL) or head nods (in LSF) are not really explained by the notion of 'greater effort' - after all, one could just as well expend effort by leaning backwards, or sideways. Similarly, longer duration per 
se (in both modalities) might not be the most perspicuous way to signal greater effort. A better generalization might be that the spoken and the signed modalities both make use of a 'salience code' whereby focused elements are made more easily perceptible holding a sign longer and leaning towards the addressee to realize it are presumably ways to make a sign more easily perceptible.

4. Fourth, in ASL and LSF alike, raised eyebrows are a regular marker of focus - a standard result in the literature on ASL (Wilbur 2012). Future research should (i) compare this finding with the raised eyebrows found as co-speech gestures co-occurring with focus in Dohen 2005 and Dohen and Loevenbruck 2009, and possibly (ii) explore broader cognitive effects of raised eyebrows to determine whether and how they should be integrated to an 'effort' or 'salience' code (see Elliott and Jacobs 2013).

Several questions remain for future research. First, one should try to replicate our findings with more consultants, and determine whether the differences we found between our ASL and our LSF data are differences between individual signers or between languages ${ }^{21}$; similarly, one might use more sophisticated methods to assess the various manual and non-manual modifications studied here - a non-trivial undertaking (see for instance Wilbur and Martínez 2002 on sign speed). Second, one should seek to tease apart the role of different markers, which were lumped together in the present study. Third, the case of exhaustive focus should be revisited to determine why in ASL and LSF alike 'standard' disjunction gives rise to clear exclusive readings, whereas other varieties of disjunction sometimes display a different behavior. Finally, it would be interesting to determine what is the relation, if any, between the head nods found in our LSF data and the forward leans described for ASL. 


\section{References}

Caponigro, Ivano, and Kathryn Davidson. 2011. Ask and tell as well: Clausal questionanswer pairsin ASL. Natural Language Semantics 19(4): 323-371.

Chierchia, Gennaro, Danny Fox, and Spector Benjamin. 2012. The Grammatical View of Scalar Implicatures and the Relationship between Semantics and Pragmatics. In Semantics: An International Handbook of Natural Language Meaning, ed. by Paul Portner, Claudia Maienborn, and Klaus von Heusinger, 3: 2297-2332. Berlin, NewYork: Mouton de Gruyter.

Crasborn, Onno, and Els van der Kooij. 2013. The phonology of focus in Sign Language of the Netherlands. Journal of Linguistics 49(3): 515-565.

Dachkovsky, Svetlana, and Wenday Sandler. 2009. Visual Intonation in the Prosody of a Sign Language. Language and Speech 52(2-3): 287-314.

Dohen, Marion. 2005. Deixis prosodique multisensorielle: Production et perception audiovisuelle de la Focalisation contrastive en français. Doctoral dissertation, Institut National Polytechnique de Grenoble.

Dohen, Marion, and Hélène Loevenbruck. 2009. Interaction of audition and vision for the perception of prosodic contrastive focus. Language \& Speech 52(2-3): 177-206.

Elliott, Eeva A., and Arthur M. Jacobs. 2013. Facial expressions, emotions, and sign languages. Frontiers in Psychology $\quad$ in 115. http://dx.doi.org/10.3389/fpsyg.2013.00115

Geurts, Bart. 2011. Quantity Implicatures. Cambridge University Press.

Gussenhoven, Carlos. 2001. Intonation and biology. In Liber Amicorum Bernard Bichakjian, ed. by Jacobs, Haike \& Wetzels, W.Leo 59-82. Maastricht: Shaker.

Gussenhoven, Carlos. 2004. Phonology of Tone and Intonation. Cambridge University Press.

Katz, Jonah, and Elisabeth Selkirk. 2011. Contrastive Focus vs. Discourse-New: Evidence from Phonetic Prominence in English. Language 87(4): 771-816.

Katzir, Roni. 2013. A note on contrast. Natural Language Semantics 21(4): 333-343. 
Kimmelman, Vadim. 2014. Information structure in Russian Sign Language and Sign Language of the Netherlands. Doctoral dissertation, University of Amsterdam.

Kimmelman, Vadim, and Roland Pfau. To appear. Information Structure in Sign Languages. In The Oxford Handbook of Information Structure, ed. by Féry Caroline and Shinichiro Ishihara. Oxford: Oxford University Press.

Kuhn, Jeremy. To appear. ASL Loci: Variables or Features? Journal of Semantics.

Lillo-Martin, Diane, and Ronice M. de Quadros. 2008. Focus constructions in American Sign Language and Lingua de Sinais Brasileira. In Signs of the time. Selected papers from TISLR 8, ed. by Quer Josep, 161-176. Hamburg: Signum.

Rooth, Mats. 1996. Focus. In Handbook of Contemporary Semantic Theory, ed. by Lappin Shalom, 271-297. Blackwell, Oxford.

Schlenker, Philippe. 2013. Temporal and Modal Anaphora in Sign Language (ASL). Natural Language and Linguistic Theory 31(1): 207-234.

Schlenker, Philippe. 2014. Iconic Features. Natural Language Semantics 22(4): 299356.

Schlenker, Philippe. To appear. Super Monsters - Part I. Semantics \& Pragmatics.

Schlenker, Philippe, Jonathan Lamberton, and Mirko Santoro. 2013. Iconic Variables. Linguistics \& Philosophy 36(2): 91-149.

Schwarzschild, Roger. 1999. GIVENness, AvoidF and other Constraints on the Placement of Accent. Natural Language Semantics 7(2): 141-177.

Vallduví, Enric. 1992. The informational component. NewYork: Garland.

Wilbur Ronnie B.. 1999. Stress in ASL: Empirical Evidence and Linguistic Issues. Language and Speech 42(2-3): 229-250.

Wilbur Ronnie B.. 2012. Information structure. In Sign language. An international handbook (HSK - Handbooks of linguistics and communication science), ed by Pfau, Roland, Markus Steinbach \& Bencie Woll, 462-489. Berlin: Mouton de Gruyter.

Willbur, Ronnie B. and Patschke, Cynthia. 1998. Body leans and marking contrast in ASL. Journal of Pragmatics, 30, 275-303. 
Wilbur, Ronnie B. and Martínez, Aleix M. 2002. Physical correlates of prosodic structure in American Sign Language. M. Andronis, E. Debenport, A. Pycha \& K. Yoshimura (eds.), Chicago Linguistic Society 38, 693-704.

\footnotetext{
"Many thanks to Emmanuel Chemla and to Ronnie Wilbur for helpful discussions. We greatly benefited from the detailed remarks of three anonymous referees, as well as of the Editors of the 'squibs' section of Linguistic Inquiry.

Authors' contributions: Schlenker initiated the project, elicited the data, provided the analysis and wrote the paper. Schlenker, Lamberton, Aristodemo and Santoro jointly developed the /notation used to transcribe manual modulations and non-manuals. Lamberton was the native consultant for the ASL data, which he also transcribed. Ducasse was the native consultant for the LSF data, and he also provided advice about their transcription. Aristodemo and Santoro transcribed the LSF data. Averages mentioned in the text were checked by Lucie Ravaux, who also helped prepare the references.
}

Video references: each paradigm or example is followed by the reference of the video on which the sentences were recorded. For instance, ASL, 21, 5 refers to video 52 of the ASL folder 21, and $L S F, 44,56$ refers to video 56 of the LSF folder 44 .

Grant acknowledgments: The present work was supported by an Advanced Grant of the European Research Council ('New Frontiers of Formal Semantics'). The research reported in this piece also contributes to the COST Action IS1006. Three of the authors' home institution, Institut d'Études Cognitives (of which Institut Jean-Nicod is a member), is supported by grants ANR-10-LABX-0087 IEC and ANR-10-IDEX-0001-02 PSL*.

${ }^{1}$ The exclusive reading may be analyzed as a variety of lexical enrichment (Geurts 2011) or as association with a covert exhaustivity operator (Chierchia et al. 2012). The latter analysis requires and the former makes plausible that alternative activation is involved in the process. 
${ }^{2}$ In alternative semantics, one might want to reinterpret Gussenhoven's effort code as follows: focus on an element $E$ indicates that $E$ has greater importance because one needs to evaluate both $E$ itself and its alternatives.

${ }^{3}$ See Wilbur and Martínez 2002 for a more detailed discussion of the respective roles of velocity, acceleration (= the first derivative of velocity) and jerk (= the second derivative of velocity) in marking prominence in ASL.

${ }^{4}$ Importantly, Ducasse's remarks during judgment tasks in elicitation sessions suggest that mouth and eye modifications are relevant to the expression of focus as well. Some instances of eye modifications are by-products of eyebrow raising, but it might be that not all are. We leave this question, as well as that of mouthing, for future research, and do not attempt to transcribe these modifications in this piece.

${ }^{5}$ See the following site for more information on the /-notation: https://sites.google.com/site/linguaeparis/sign_language_slash_notation

${ }^{6}$ Crasborn and van der Kooij find that height plays a role in marking focus on fingerspelled letters. This might be the case with $J$ in (4)b and with $J_{\text {OHN }}$ in (6)d, but not of the other focused letters in these examples. The contrast might be due to the fact that $J$ involves a rotation, hence a sizable movement, whereas other letters do not.

${ }^{7}$ Note that (3)c-d both gave rise to scores of 3 and 6 . We do not know why these variations arose, but note that on all trials (3)c was strictly preferred to all other sentences. (Note also that in (3)-(4) the written context given to the consultant erroneously had 'three-letter sequences' in lieu of 'four-letter sequences'; this was corrected in the text.)

${ }^{8}$ (5)a-d both gave rise a 3-point difference between the lowest and the highest score. But here too, on all trials (5)b was strictly preferred to all other examples.

${ }^{9}$ While all proper names are signed towards the center of signing space, there are slight positional differences - within the central area, they tend to be signed from left to right. The same remark applies to example (13) and (14) below, as well as to (15)a,b and to (16)a,b.

${ }^{10} \mathrm{We}$ attempted to obtain the same pattern with the mentioned word $O R$, as in (i) (obtained from different videos); we give at the beginning the two judgments we obtained (session 1, session 2):

(i) Context: The speaker teaches LSF to a beginning student. 


\begin{abstract}
IX-1 WANT IX-2 SIGN $\left[\begin{array}{ll}4 & \text { WORD }\end{array}\right]_{a}$ THEN $\left[\begin{array}{llllll}4 & \text { WORD }\end{array}\right]_{b}$ [YES NO ADD IMPOSSIBLE $]_{a}$
$\begin{array}{lll}\text { a. } 77 \text { THEN [YES NO OR IMPOSSIBLE }]_{\mathrm{b}} & (44,66)\end{array}$

b. 17 [_+YES NO OR IMPOSSIBLE $]_{b} \quad(44,67)$

c. 17 [YES -+$\}^{\wedge} \overline{\mathbf{N O}_{-}}$OR IMPOSSIBLE $]_{\mathrm{b}} \quad(44,68)$

d. 77 [YES NO $\quad+\}^{\wedge}$ IOR IMPOSSIBLE $]_{b} \quad(44,69)$

e. 77 THEN [YES NO OR $=\overline{\text { IMPOSSIBLE_ }}$ ] $(44,70)$

'I want you to sign 4 words, then 4 other words: first, 'YES', 'NO', 'ADD', 'IMPOSSIBLE', then 'YES', 'NO', 'OR', 'IMPOSSIBLE'. (LSF)

In session 1, we obtained the expected pattern in b., c., d., though unexpectedly e. was acceptable. In session 2 (where the consultant re-assessed the videos from home, nearly 2 months after the first session) everything became acceptable, but the consultant added notes about the meanings that made it clear that the emphasis was itself quoted - for instance YES became 'highly affirmative', $O R$ became exclusive, etc.
\end{abstract}

${ }^{11}$ Eyebrow raising on the focused element is different from that on the if-clause. The latter involves a tension of the muscles in the area between the eyebrows while the former involves raised eyebrows only.

${ }^{12}$ Under $I F$, which is downward-entailing, the derivation of an exclusive reading for $O R$ requires the insertion of an embedded exhaustivity operator in the framework of Chierchia et al. 2012 (without local strengthening, the literal meaning of if $p$ or $q$, $r$ will entail that when $p$ and $q$ both hold, $r$ holds as well; a matrix exhaustivity operator will yield a stronger reading and will thus preserve this entailment). Under $B E T$, things are less clear because a matrix exhaustivity operator might conceivably yield a related effect (this depends on the precise truth conditions of sentences such as I only bet that Ann OR Bill will come vs. I bet that only Ann OR Bill will come). Be that as it may, our sign language data show that under $I F$ and $B E T$ alike, focus has clear truth-conditional effects.

${ }^{13}$ On the second trial, our consultant added the following remark: 'some people might interpret the emphasis on $O R$ as being opposed to $A N D$, thus they would think both could show up and speaker would still win his bet'. The same remark was made regardingf other examples involving focused disjunctions of different varieties.

${ }^{14}$ Two remarks should be added. First, our informant had similar judgments with conditionals that involved no word for IF (but just non-manual markers on the if-clause; 44, 27). Second, in our very early work on focused vs. unfocused $O R$ in LSF, we failed to detect a truth-conditional 
contrast, as even unfocused $O R$ appeared to be exclusive under $I F$. This failure might be due to the fact that the semantic task was administered differently: instead of specifying a situation and asking an inferential question, we asked the consultant to select from a list of situations those that would license a certain inference (e.g. 'In which of the following situations must the speaker give 20 euros to the addressee?' $(42,10)$.

${ }^{15}$ In our LSF data (which differ in this respect from our ASL data), the eyebrow raise accompanying the focused constituent is very similar to the eyebrow raise accompanying the ifclause, the only difference being that the former is more pronounced than the latter.

${ }^{16}$ Note that (15)d gave rise to a 3-point difference between the lowest and the highest score, but that in all trials it had a much lower score than other sentences of the paradigm.

${ }^{17}$ When we tested contrastive focus on $O R-I X-I X$, as in (i), we did not get consistent results; but in each case the result was far more acceptable than in (15)d-(16)d.

(i) Context: The speaker teachers LSF to a beginning student.

\{7 IX IX-1 WANT IX-2 SIGN [4 WORD] $]_{\mathrm{b}}$ THEN [4 WORD $]_{\mathrm{a}}-$ ['YES' 'NO' 'ADD' 'IMPOSSIBLE'] THEN

$7^{\{777\}}$ [YES NO OR-IX-IX IMPOSSIBLE]

b. $5^{\{645\}}$ [YES NO +OR-IX-IX IMPOSSIBLE]

'I want you to sign four words and then four words again, namely: 'YES', 'NO', 'ADD', 'IMPOSSIBLE', and then 'YES', 'NO', 'OR-IX-IX', IMPOSSIBLE'. (LSF, 44, 71; 3 judgments)

${ }^{18}$ This might be because the disjunction is in the wrong position to allow for an alternative to be generated with a conjunctive meaning. This hypothesis is plausible, but dependent on a more detailed analysis of possible alternatives - the word THE-TWO could in fact appear in a postnominal position and would yield the desired conjunctive meaning $(44,60)$; hence this expression should somehow not count as an alternative to the clause with $O R-I X_{a}-I X_{b}$. Note also that for the standard $O R$ found between the disjuncts, one needs to posit either that a null conjunction counts as an alternative (as this is a common way to form conjunction in LSF), or that the word $A D D$ (which has a meaning akin to conjunction) does $(44,58)$.

${ }^{19}$ As mentioned by an anonymous referee, the high ratings for the contrastive examples without focus marking in (7)a, (8)a and (10)a could suggest that focus marking is optional in these cases. We hesitate to draw strong conclusions without further evidence, however. (It is of course unsurprising that in the examples of Section 2 exhaustivity focus should not be obligatory.) 
${ }^{20}$ Interestingly, Katzir 2013 provides a purely semantic argument that suggests that the same notion of 'exclusion' is at work in contrastive and in exhaustive focus. Specifically, he argues that similar semantic constraints explain which alternatives are negated/activated in both types of focus, and that this follows if exhaustification is involved not just in exhaustive but also in contrastive focus. Briefly, his argument is in three steps, illustrated with the data in (i)-(iv). First, he shows that recent treatments of only explain why an alternative involving expensive is understood to be negated in (ii) but not in (i) (the presence of required changes some key entailments). Second, he argues that contrastive focus gives rise to analogous distinctions, but in terms of acceptability rather than truth conditions: marking expensive as contrasting with red is acceptable in (iv) but not in (iii). Finally, he hints that these cases can be unified if contrastive focus involves a covert only, with the requirement that the clause with the focused element (and the covert only) should exclude the meaning that would be obtained if the antecedent element had been repeated instead. Thus He enly brought a RED convertible in (iii) fails to exclude $\mathrm{He}$ brought an expensive convertible because of the inferential facts in (i). By contrast, in (iv), John is enly required to bring a RED convertible does appropriately exclude John is required to bring an expensive convertible - because of the inferential facts in (ii).

(i) John only owns RED convertibles. $\Rightarrow$ John doesn't own blue convertibles \#> John doesn't own expensive convertibles

(ii) John is only required to own RED convertibles. $=>$ John is not required to own blue convertibles $=>$ John is not required to own expensive convertibles

(iii) -Mary's uncle, who is very rich and makes expensive convertibles, came to Mary's wedding. I wonder what he brought as a present.

-He brought a CHEAP / \#RED convertible.

(iv) Mary was required to bring an expensive convertible. And John is required to bring a CHEAP / RED convertible.

${ }^{21}$ As noted, different consultants might also use our scale differently. For this reason, we do not make absolute comparisons of ratings across consultants. In particular, although sentences with focus on the 'wrong' word were often rated lower by our LSF consultant than by our ASL consultant (see for instance (3)vs. (8)), we cannot draw linguistic conclusions from this fact alone: maybe our LSF consultant was just more willing to use the bottom of the scale. 